\title{
Analysis on Translation Strategies of Hawks’ The Story of the Stone: Extractions of Dialects by Python from Hongloumeng
}

\author{
GONG Yi-pu, CHEN Bing \\ Sichuan Technology and Business University, Chengdu, China
}

\begin{abstract}
Xueqin Cao's Hongloumeng is recondite, yet always arousing passions in China and even the whole world in deep and significant ways. As media-translation and the transmission of Hongloumeng go abroad, Redology has already developed into a diffuse academic field of study internationally. The locution in this masterpiece is magnificent, especially in the profound implications of its use of dialects, which are profuse and executed with exceptional literacy as well as aesthetic acuity. However, the specific strategies on how to translate the dialects may directly influence Western readers' appreciation of the masterful literary aesthetics. Currently, most scholars compare the translation research of dialects using different translation theories and analyze the respective gains and losses. Coded in Python, computer algorithms have also been written employing various translation theories, but thorough interdisciplinary, comparative analyses of the data are rare. Using the relative content as well as data integration of dialects in the first 80 chapters, this paper examines how the dialect translations in Hawks's The Story of the Stone are undertaken and then follows up with manual proofreading of the data from the algorithms. In terms of the analysis on crawling data, reconsidering Hongloumeng with Python programming may contribute to a deeper understanding of some of the dialect words, and provide acute insight into translation strategies and the process of the translator.
\end{abstract}

Keywords: Honglongmeng, dialects, Python, translation strategies

\section{I . Overview of Dialect in Hongloumeng}

Hongloumeng is regarded as a foundational masterpiece in Chinese classical literature. The profound cultural connotation and fascinating locution had a tremendous effect on subsequent literary compositions. The diversification in dialects has been an authoritative template for researchers in Redology. Since The Story of the Stone by David Hawks \& John Minford came out, all kinds of research on its translation versions have proliferated. Mr. Bufan Dai has commented in his works that, "There are abundant dialects not only from the Northern part of China, but also quite a lot from Jiangsu and Zhejiang provinces and the city of Shanghai which is called Wu in Hongloumeng" (Dai, 1979, p. 1). Mr. Wenbin Hu has stated in his works that the main body of the language and the rhythm, flavor, as well as grammatical structures in Hongloumeng are Beijing dialect-centered

GONG Yi-pu, Master of Arts \& doctoral student in English, Translation and linguistics, Foreign Language Department, Sichuan Technology and Business University.

CHEN Bing, Master of Software Engineering, Computer Science, Educational Administration Department, Sichuan Technology and Business University. 
and also absorb lot of dialects from the northern part of China, including sprinklings of Mongolian and Manchu vocabularies. Meanwhile, quite a few dialects from south of Yangtze River also exist in this masterpiece in service of the plot and characters (Hu, 2009, pp. 99-106). According to Liuxiaoan, Liuxuemei's research, the number of relative papers on dialects in Hongloumeng achieved 38 (2012 contained \& previously), in which there are 5 articles involving official dialect and 8 involving Beijing dialect as well as 13 articles involving dialects around Yangtze River and Huai River. Libei has her statement on dialects in Overview of Linguistics Research on <Hongloumeng>, including both the interiority of language as well as its structures, dialects, vocabularies and research on some concrete sentence patterns in Hongloumeng (Li, 2001, pp. 313-315).

\section{David Hawks and Minford's The Story of the Stone and the Translation on Dialects}

Since the inception of David Hawks and Minford's The Story of the Stone, which stunned academics in Western sinological fields, most of the translation strategies on dialects in the first 80 chapters of The Story of the Stone concern manners of domestication, wherever the dialects are from, Beijing, Wu or somewhere else. David Hawks has indicated in his essay the original version of The Story of the Stones is Version Cheng of Hongloumeng, 120 Chapters-Manuscript of Hongloumeng in the QianLong Dynasty (Hawks, 1989, p. 159). So the research on translation strategies in this paper also take the original version as its subject. According to the comparative data from journals embodied in CNKI, the number of renowned studies of dialectal translations on Hongloumeng is still few. Hao Weijuan made analysis and interpretation through illustration and functional equivalence theory on dialectal translations for Hawks' The Story of the Stone in her Research on Dialectal Translations in <Hongloumeng $>$ (Hao, 2011, p. 19).

According to the source criticism and consensus proved, the writing time of Hongloumeng is almost as same asthe background time in the plot. Meanwhile, the dialects and diction in monologue used by the author is extremely similar to that in plot. As a result, the samples of dialectal diction in this essay are sourced from the narrative as well as the dialogue among characters.

In the paper, the main combinations of different word classes have been encapsulated into the dictionary and serve as parameters of the Python's CYCLE---- "for". All of this information has been submitted to the database of Chinese-Classification researched and developed by HLIPCA in Beijing Institute of Technology for "Post" request. And then the extractions of textual information from returning values will be generated. If repetition and misjudgment of dialectal word class happen, the smart filter will work to exclude them. Meanwhile, comparison among the translation strategies on repetitive dialect in The Story of the Stone will be made. The specific samples of different translations of the same dialects will be illustrated in Chapter IV. After this step, manual proofreading will be done as a final check. In this essay, the analysis of typical dialectal cases in the first 80 chapters of The Story of the Stone focuses on Hongloumeng's Cheng version in Qianlong dynasty. Artificial proofreading refers to Xinzhen Liu's Dictionary of Dialects and Difficult Diction in $<$ Hongloumeng $>$ and some materials in Shuren Dong's New Edition of Beijing Dialect Dictionary. The dialectal diction of Hongloumeng crawled by Python in this paper only focuses on those which are in obvious word formation regulations. In the interest of expediency, the specific samples will be limited in scope.

Python is the preferred programming medium. Along with the attribution of intelligibility, succinctness, iteration as well as scalability for programming language, Python is also easier to use than Java, C++ which is 
why it is warmly welcomed in the fields of education and translation. When literary works are under the magnifying glass of Python, the contextual paraphrase will be generated in an intuitive view. The data obtained will be a feedback and reflection on the translations of context. The algorithm of Python in this paper is mainly concerned with filtration on word class(part of speech) collocation of unconventional diction. For instance,

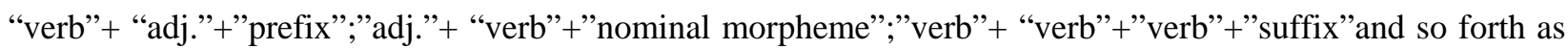
the ways of permutation on dialect as well as data-crawling. The specific code in the algorithm is as follows:

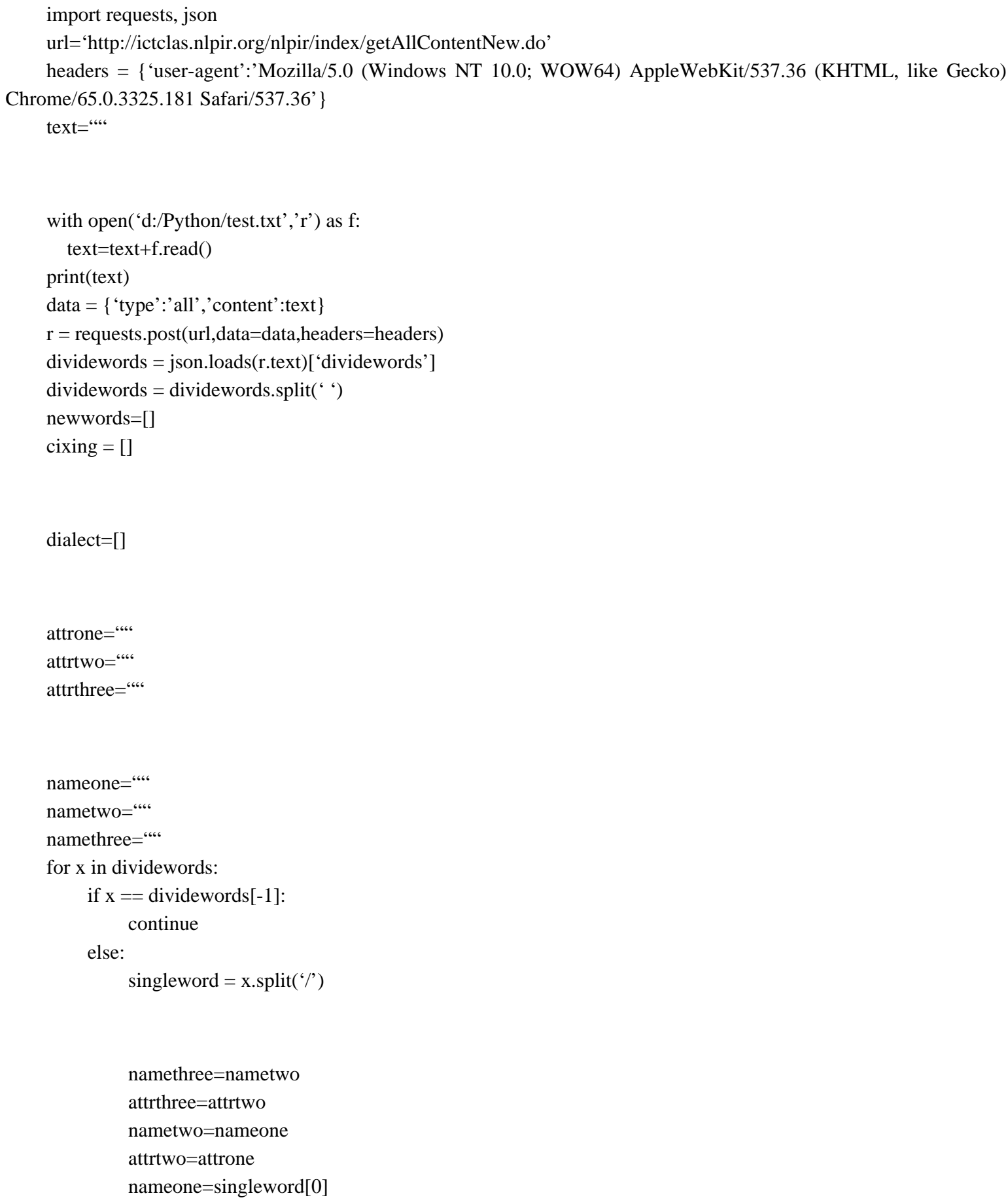


attrone $=$ singleword[1]

if attrthree=="d" and attrtwo=="a" and attrone=="ng": dialect.append(namethree+nametwo+nameone)

if attrthree=="a" and attrtwo=="nr1" and attrone=="ng": dialect.append(namethree+nametwo+nameone)

if attrthree=="d" and attrtwo=="v" and attrone==“n": dialect.append(namethree+nametwo+nameone) if attrthree=="a" and attrtwo=="v" and attrone=="n": dialect.append(namethree+nametwo+nameone) if attrthree=="v" and attrtwo==" $\mathrm{v}$ " and attrone=="k": dialect.append(namethree+nametwo+nameone) if attrthree=="v" and attrtwo=="n" and attrone=="ng": dialect.append(namethree+nametwo+nameone)

if attrthree==" q" and attrtwo=="vi" and attrone=="n": dialect.append(namethree+nametwo+nameone if attrtwo=="p" and attrone=="ng": dialect.append(nametwo+nameone) if attrtwo=="v" and attrone==" $\mathrm{v}$ ": dialect.append(nametwo+nameone)

newwords.append(singleword[0]) ، ،

judgement on reduplicating words ،

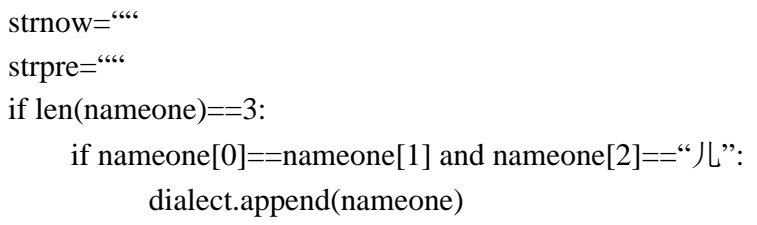

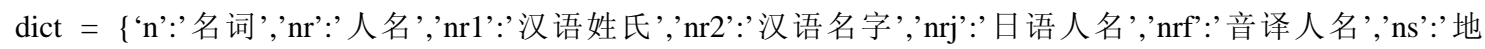

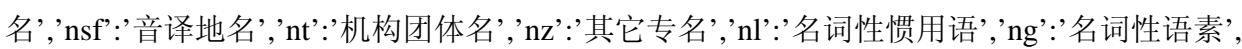




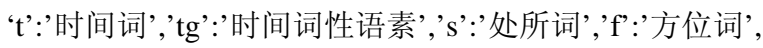

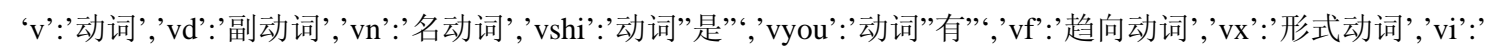
不及物动词 (内动词) ', 'vl':'动词性惯用语', 'vg': '动词性语素',

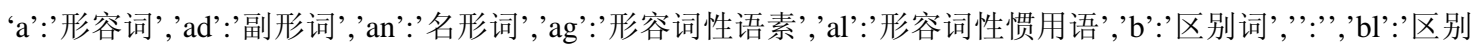
词性惯用语', 'z': 状态词',

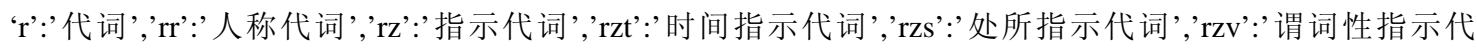

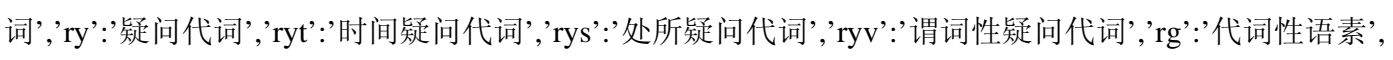

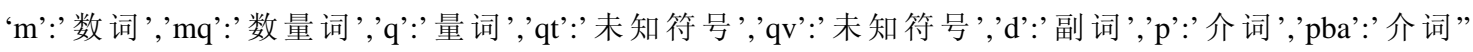
把”','pbei':'介词”被”, ', ','连词','cc':'并列连词',

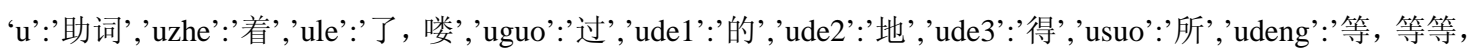
云云','uyy': 一样, 一般, 似的, 般, 'udh':'的话, 'uls': 来讲, 来说, 而言, 说来','uzhi':'之','ulian':'连',

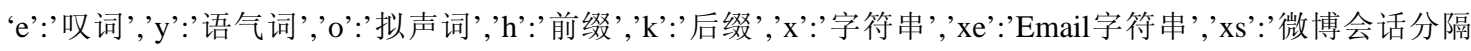
符,',xm':'表情符合','xu': '网址URL',

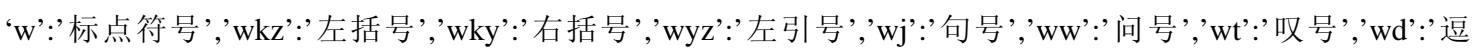

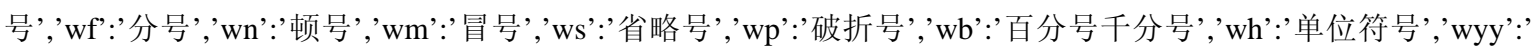
双引号'

\}

dialectlist=“

for $\mathrm{s}$ in dialect:

dialectlist $=$ dialectlist + s $+\%$

$\operatorname{print}(($ 'n 方言是: '+dialectlist+'。')

cixinglist $=$ “

for y in cixing:

cixinglist $=$ cixinglist + dict $[y]+{ }^{\prime \prime}$ ' (Matthes \& Yuan, 2017, pp. 70-79, 123)

Due to the limited space of article, the excerpt above is a section of basic code. According to the judgment on dialectal phrases by means of algorithm of Python and the contextual influence on parameters of dialectal diction, the terminal dialectal phrases could only be displayed normally after data-cleaning. So, filter (function) will be added to the algorithm for the exclusion of (unwanted) data. Seeing that regional factors exist in the same dialects among different regions, the readers' comprehension and experience of the piece will be duly impacted. Further understanding will be ascertained through references to the paraphrases in The Story of the Stone.

\section{Analysis on Hawks' Translation Strategies Based on Extractions of Dialect by Python}

Taking Cheng Jia Version \& ZhiPi version's Hongloumeng as the original draft and ChengYi version as reference to extract the case after imitation of word-formation on dialects. The specific data of relative dialects through the judgment by Python as well as exclusion by filter are as follows:

“打牙儿”、”打千儿”; ”直过儿”、”像生儿”、”倒扁儿”; ”打抽丰”、”打擂台”; ”刚刚儿”、”热刺 刺”、”蝎蝎蟄蟄”; ”阿物儿”等。 
Sample 1: 第三十七回中, ”袭人笑道: , 你们这起烂了嘴的！得空儿就拿我取笑打牙元, 一个个不 知怎么死呢...”

Translation: 'Wicked girls!'said 'Flowers' Aroma, laughing in spite of herself, 'taking my name in vain! Whenever you've got a few moments to spare you are making fun of me. There’s not one of you that will come to a good end!'

During the rendition, “打牙儿” means "tease”, “bicker”. Hawks take measures of domestication and translate “打牙儿” and the subsequent “取笑” into “making fun of me”. Before this there is an additional translation "taking my name in vain” which should be regarded as a meaning extension (Liu, 2010, p. 238). It is helpful for the readers to discern the subtle difference in meaning between “取笑” and “打牙儿”. The tone of the characters in the original masterpiece is hereby enhanced and with meaning of reproof.

Sample 2: In chapter 8,9,14,52 and 64, there is an old Manchu etiquette on asking for greeting- "Da qian" (Dong, 2010, p. 89). All are generally translated summarily as "saluted Manchu fashion” or "in the Manchu salute" except for chapter 64, in which Hawks translated it in domestication as "touched hand and knee to the ground in greeting." Above all else, as a specific dialectal proper noun, it is de jure to be translated into noun phrases summarily. However, when this dialect appeared one last time, Hawks chose to describe this action flow to the readers in detail, which can be viewed as a summary of "terminology" that appeared several times before; the intention of which is obvious and reasonable.

Sample 3: In chapter 24, “上世仁冷笑道: ’...况且如今这个货也短, 你就拿现银子到我们这小铺子 里来买, 也还没有这些, 只好倒扁儿去, 这是一件...”,

Translation: 'In any case, we're short of stock on those two items. I doubt we've got that much in the shop, even if you could pay cash down for it. We'd have to try to raise it for you elsewhere.'

In Beijing Dialect Dictionary, here the bulleted dialect “倒扁儿” means “temporary short-term borrowing to help with liquidity in case of emergency or sometimes a loan from a third party” (Chen, 1985, p. 54). In The Story of the Stones, Hawks approached it with a domestication strategy, which portrayed in terms of the actual action in that era and even many Chinese readers who don't understand Beijing dialect can also experience this as a foreign language, not to mention the non-native Chinese readers. Although domestication strategy will weaken the dramatic effect in local dialects, it is easy to understand for English readers.

Sample 4: 第三十四回中, ”袭人连忙回道: ’...心不顺, 就没有忌讳了。二爷将来倘或有人说好, 不过大家落个直过儿; 若叫人哼出一声不是来...”

Translation: In chapter 34,... said Aroma hurriedly.”If they feel well-disposed towards you, they'll make you out to be a saint; but if they are not, then Heaven help you! If Master Bao lives to be spoken well of, we can count ourselves lucky; but the way things are, it only needs someone to breathe a word of scandal and..."

In Chinese Dictionary, "zhiguoer”means “not successful, or not failed”; Dictionary of Dialects and Difficult Diction in <Hongloumeng > it means "nothing wrong, but not meritorious work." Hawks translated it into "count ourselves lucky" through extended free translation, which complements the helplessness and irony in the conversation. Although it is free translation, the flavor of Chinese northern dialect has been preserved well. 
Sample 5: 第三十五回中, ”宝钗原是掩面而哭, 听如此说由不得也笑了, 遂抬头向地下啐了一 口, 说道: 你不用做这些像生儿了。我知道你的心里多嫌我们娘儿们......”

Translation: In chapter 35, the clumsiness of his apology rapidly turned Bao-chai’s weeping into laughter. Lifting her face up from the handkerchief in which it had been buried, she made a little grimace of derision.' There's no need for you to put on this act,' she said. 'I understand what your real motive is perfectly well ...'

Among them, "Xiang sheng er" in the Modern Chinese Dictionary refers to "Chinese folk talk," which causes the audience to laugh with jokes, funny questions and answers, rap, imitation so on and so forth. Hawks also translated his interpretation into "to put on this act" according to the connotation of the actual action, and interprets the substantive connotation of the dialect, which can not only contribute to the restoration of the scenes in the original masterpiece to readers, but also make the description of the context in translation lifelike.

Sample 6: 第五十三回中, ”贾珍道: ’我说呢, 怎么今儿才来! 我才看那单子上, 今年你这老货又 来打擂台来了 ...”吸”贾珍绉眉道: ‘我算定你至少也有五千银子来，这够做什么的? 如今你们一共只剩了八九个庄子, 今年倒有两处报了旱潦, 你们又打擂台, 真真是叫 别过年了! ...”

\section{Two Pieces of Translation:}

In chapter 53, 'I was wondering what could have made you so late,'said Cousin Zhen. 'Well, I've been looking at this list of yours. I see you're holding out on me again this year, you old devil.'; 'I'd reckoned on your bringing me at least five thousand taels,' said Cousin Zhen, frowning. 'What am I supposed to do with an amount of those eight or nine? Two have declared themselves disaster areas this year and aren't contributing anything. With you holding back on me too, I might as well give up celebrating New Year altogether.'

The original meaning of "Da lei tai" means "fighting on the stage". According to the interpretation in Xinzhen Liu's Dictionary of Dialects and Difficult Diction in $<$ Hongloumeng $>$, "Tenants deliberately pay less money and try to tease the landowner". The author thinks that both of these two places have the meaning of "weaseling, cheating" and not paying money and grain. Hawks' translation is "holding out on me" \&"holding back on me”. In the Oxford Dictionary, it means "refusal to give (informal oral words)" and "concealment", which not only avoids repetition, but also makes use of colloquial English for a specific free translation. Wu Jinxiao's craftiness and derision in Jiazhen's mouth is lifelike and vivid by means of this translation strategy.

Sample 7: 第三十九回中, ”只见凤姐儿不在屋里, 忽见上回来打抽丰的刘老老和板儿来了, 坐在 那边屋里...”

Translation: When she got there, however, it was not Xi-feng she found waiting for her, but the old countrywoman she had admitted on a previous occasion as a suppliant, Grannie Liu, with her little grandson Ban-er...

In The Modern Chinese Dictionary, “打抽丰” means the rich men are dunned for some pretext in previous times, which also with the name of "seek profits”, as well as another Chinese dialect “打秋风”. Therefore, Hawks took free translation strategy in generalization for "as a suppliant”. By which may bring readers a more concise and intelligible understanding but lost the original connotation "be with a good name for it" and the effect of covering up the shyness and shame. 
Sample 8: 二十六回中, ”冯紫英笑道: '......说着撒手就走。薛蟠道: 越发说的人热刺刺的扔不 下，多早晚才请我们......”

五十七回中，”薛姨妈劝道：＼cjkstart宝玉本来心实，可巧林姑娘又是从小儿来的，他姊妹两 个一处长得这么大，比别的姊妹更不同。这会子热刺刺的说一个去，别说他是个实心 的傯孩子......”

\section{Two Pieces of Translation:}

In chapter 26: Feng Zi-ying laughed:' ... ....'He made a determined movement towards the door. 'Now you've got us all peeing ourselves with curiosity!' said Xue Pan.

“热刺刺” has a similar meaning with “feverish, fiery and hot” in The New Edition of Beijing Dialect Dictionary, paraphrased as "sorrow in reluctance of parting”, “刺” is with the meaning of "perverseness” in Modern Chinese Dictionary. So “热刺刺” can be considered as “be on tenterhooks”. “Pee oneself” means “wet one's underpants by urinating involuntarily (Often used to suggest the notion of losing control of oneself through fear or hilarity)" in Oxford Dictionary. So Hawks translated the dialect humorously by means of the complement to free translation. Meanwhile, through the same method, the boulevardier image of "Foolish Xue" as well as his educational level are extremely to the point. Both of these contribute to a better understanding for readers of Xuepan's disposition.

The “热刺刺” here was translated into "suddenly out of the blue” by concrete free translation, which highlighted Baoyu's deep feelings for Daiyu at that time and served as a finishing touch.

Sample 9: 五十一回中, ”晴雯忙回身进来, 笑道: ’那里就唬死了他了? 偏惯会这么蝎蝎蟄蟄老婆 子的样儿。”;

五十二回中，”宝玉忙道：＼cjkstart这如何使得？才好了些，如何做得活！’晴雯道：，不用你蝎 蝎蟄䖯的, 我自知道。”,

六十七回中，”忽然想到宝钗系王夫人的亲戚，为何不到王夫人跟前卖个好儿呢？自己 便蝎蝎䖯䖯的，拿着东西，走至王夫人房中...”

\section{Three Pieces of Translation:}

Chapter 51: Immediately Skybright ran in again. 'What an old woman you are !'she said. 'The shock wouldn't have killed her.'

Chapter 52: 'Oh, don’t be such an old woman !' said Skybright. 'I know what I’m capable of.'

Chapter 67: Presently the thought occurred to her that Bao-chai was close kin to Lady Wang. Why should she not take advantage of that fact to ingratiate herself with Lady Wang? Gathering the articles up in her arms, she went off, full of fuss and self-importance, to Lady Wang's room and...

The meaning of “蝎蝎䖯蟄” in The New Edition of Beijing Dialect Dictionary is “carry-on” (Dong, 2010, p. 499), almost as alike as those in chapter chapter 51 and 52. Therefore, Hawks translated both of the “蝎蝎蟄蟄” in similar strategy of free translation into "What an old woman you are!” and “Oh, don’t be such an old woman!”; However, according to the actual disposition and psychological state of Aunt Zhao, Hawks translated this dialectal phrase by complementary free translation strategy into "full of fuss and self-importance”. It is evident 
that Hawks has a deep understanding of the portrayal in characters, and the translation plays a tremendous role in Aunt Zhao's status in Jia's family and the enhancement of the sense in frame.

Sample 10: 第十九回中, ”李嬤嬤听了, 又气又愧, 便说道: '……你们看袭人不知怎么样, 那是 我手里调理出来的毛Y头, 什么阿物儿! ”

第四十二回中, ”老嬤嬤请贾母进幔子去坐, 贾母道: ’我也老了, 那里养不出那阿物 儿来, 还怕他不成...”;

四十三回中, ”尤氏笑道: ,你这阿物儿, 也忒行了大运了 .....”

\section{Three Pieces of Translation:}

Chapter 19: Nannie Li was angry and embarrassed at one and the same time. '... And as for that Aroma. I don't know what sort of a wonderful creature you think she is---- a little bit of a girl I picked out myself and trained with my own hand!'

Chapter 42: The old women in attendance on Grandmother Jia urged her to conceal herself behind the curtains of the summer-bed. But Grandmother Jia refused to budge. 'I'm old, too, woman- old enough to be his mother, I shouldn't wonder. What have I got to fear from him at my age?..'

Chapter 43: 'You really are the limit, you know,' said You-shi. 'Fortune’s darling!...'

In Dictionary of Dialects and Difficult Diction in <Hongloumeng>, only the “阿物儿” in chapter 19 has been embodied and the paraphrase is "what is it”(in a sneer) (Xinzhen Liu 2010: 151). However, it is not embodied in The Modern Chinese Dictionary, Cihai, and The Beijing Dialect Dictionary. In chapter 19, “阿物 儿” is with the meaning of “unsuitable subordinate person” in Mother Li's mouth, and was translated by Hawks into "a little bit of girl” by means of free translation.

“阿物儿” has been translated into “what have I got” firstly by means of omission strategy in chapter 42, and subsequently there is another added translation as "I shouldn't wonder”, which echoes another kind of free translation. Although the finesse of tone and emotion in the original text gets lost here, the main meaning is still conveyed.

According to the context, the “阿物儿” in chapter 43, is in extended free translation as “be the limit”, which is paraphrased as an informal oral English "be intolerably troublesome or irritating" in Oxford Dictionary (Hornby \& Li, 2018). By the way, during that time, the relationship between Youshi and Wangxifeng is still harmonious, so"阿物儿” here is opposite in meaning to the two previous references. Hawks made the translation here lifelike and which didn't really mean "wearing and tiring.” It's similar to taking advantage of English dialects and translating them into Chinese with mots justes.

Due to the limited space and the fact that combination models of word class constructed by Python code are only in a few kinds of classicaland representative meanings, the cases and analysis will stop here.

\section{IV.Conclusion}

By means of extractions of dialectal diction in Python, a set of two to four character dialects with strong rules in part of speech have been in arrangement and combination. These dialectal cases (which appear repeatedly in Hongloumeng) are listed and compared in analysis for Hawks' translation strategies. Most of them are in free translation, that is, domestication strategy. Although free translation strategy makes translation in line with the 
expressive habit of target language and reads more familiar to readers for a better fluency, there are many wonderful dialects that have been "filtered out" of their original cultural characteristics, resulting in the loss of the essence and meaning of the dialects. According to JianzhongGuo, "the differences between Chinese and English cultures sometimes make it difficult to preserve the source in the translation” (Guo, 1998, pp. 12-19). As he said, Hawks' translation strategy leads to a relatively weak trace of the culture in source language. Nevertheless, strategy of domestication can also effectively integrate Chinese as well as English culture and present it to English readers, which is helpful to the efficient understanding of the source language text.

Because the author's mastery of Python language is still limited, dialects that utilize two-word terms or expressions cannot be easily distinguished and accurately represented through the current mastered algorithm (some through the arrangement and combination on features of word class). Such as “罗喤”、“爬灰”、”满破” so on and so forth and some of which are also classical dialect cases in Hongloumeng. Finally, although there are still some misjudgments in dialect-crawling data by means of Python (such as redundant names and reduplicated dialects), it is still difficult to deal with this through the more advanced EMLo (embedded language model even if there was contextual comprehension). The reasons are as follows: first of all, the composition of dialect is complex, and the unity of codes is difficult to realize; secondly, the corpus of dialect still needs to be improved incrementally; thirdly, the confusion (ambiguity) of context caused by sequence of lexical words, etc. However, as far as the interpretation of Hongloumeng through Python is concerned, it is an emerging innovation in the field of natural language processing.

\section{References}

Cao, X. Q., \& Gao, E. (1995). A hundred and twenty Chapters manuscripts of HongLouMeng in Qianlong Dynasty. Changchun: Changchun Publishing House.

Cao, X. Q., \& Gao, E. (2014). HongLouMeng (ChengJia Edition in Qianlong Dynasty). Beijing: China Book Store Publisher.

Chen, G. (1985). Beijing Dialect Dictionary. Beijing: The Commercial Press.

Dai, B. F. (1979). Revealing the mystery of HongLongMeng's author-One of the evidences: Abundant vocabularies in Wu. The Northern Forum, (1), 1.

Dong, S. R. (2010). New edition of Beijing Dialect Dictionary. Beijing: The Commercial Press.

Eric, M., \& Yuan, Z. G. (2017). Python crash course, a hand-on, project-based introduction to programming. Beijing: Posts and Telecom Press.

Guo, J. Z. (1998). Cultural factors in translation: Foreignization and domestication. Journal of Foreign Languages, (2), 12-19.

Hao, W. J. (2017). Research on dialects translation in HongLouMeng. DaZhongWenYi, 19, 159-160.

Hawks, D. (1989). The translator, the mirror and the dream-Some observations on a new theory. In J. Minford and S.-K. Wong, (Eds.), Classical, modern and humane essays in Chinese literature. Hong Kong: the Chinese University Press.

Hornby, A. S., \& Li, X. Y. (2018). Oxford Advanced Learner's English-Chinese Dictionary (9th edition). Beijing: The Commercial Press.

Hu, W. B. (2009). Constitution and evolution of dialects in HongLouMeng-Two deserving thinking tendencies of dialectal research and proofreading in HongLouMeng. Journal of Eastern Liaoning University, (02), 99-106.

Li, B. (2011). Overview on linguistics research of HongLouMeng. Studies on a Dream of Red Mansions, (04), 313-315.

Liu, X. A., \& Liu, X. M. (2012). Index for research data classification of HongLouMeng. Beijing: National Library of China Publishing House.

Liu, X. Z. (2010). Dictionary of dialects and difficult diction in Hongloumeng. Beijing: Eastern Publishing House.

Modern Chinese Dictionary (7th edition). (2018). Beijing: The Commercial Press.

The Chinese Dictionary. (2011). Shanghai: Shanghai Cishu Publishing House. 